\title{
Improving the Summer Power Generation of a Hydropower Reservoir Using the Modified Multi-Step Ahead Time-Varying Hedging Rule
}

\author{
Soe Thiha ${ }^{1} \cdot$ Asaad Y. Shamseldin ${ }^{1} \cdot$ Bruce W. Melville $^{1}$
}

Received: 18 August 2021 / Accepted: 10 December 2021/ Published online: 26 January 2022

(c) The Author(s) 2022, corrected publication 2022

\begin{abstract}
This paper aims to improve summer power generation of the Yeywa Hydropower Reservoir in Myanmar using the modified multi-step ahead time-varying hedging (TVH) rule as a case study. The results of the TVH rules were compared with the standard operation policy (SOP) rule, the binary standard operation policy (BSOP) rule, the discrete hedging $(\mathrm{DH})$ rule, the standard hedging $(\mathrm{SH})$ rule, the one-point hedging $(\mathrm{OPH})$ rule, and the two-point hedging (TPH) rule. The Multi-Objective Genetic Algorithm (MOGA) was utilized to drive the optimal Pareto fronts for the hedging rules. The results demonstrated that the TVH rules had higher performance than the other rules and showed improvements in power generation not only during the summer period but also over the entire period.
\end{abstract}

Keywords Yeywa Hydropower Reservoir · Myitnge River · Time-varying hedging rules · Multi-objective genetic algorithm $\cdot$ Summer power generation

\section{Introduction}

The use of hedging rules has become popular in recent years as they can effectively mitigate the negative impacts of severe droughts on reservoir operation. In a hedging rule, if the current reservoir water storage plus the projected river flow into the reservoir fall below a certain critical level, the reservoir storage is raised by allowing the minor water deficits in the current period to protect against the undesirable significant water deficits which are likely to happen in the later periods.

In the context of reservoir operation, the standard operation policy (SOP) is a common rule to operate a reservoir. The SOP rule releases water to satisfy the current water demand (Tu et al. 2008), but it does not contemplate the demand in subsequent periods resulting in severe water shortages in the summer season. On the other hand, hedging rules have

Soe Thiha

sha638@aucklanduni.ac.nz

1 Department of Civil and Environmental Engineering, University of Auckland, Private Bag 92019, Auckland 1142, New Zealand 
increasingly gained more attention as it is appropriate for drought conditions. Based on the hedging stages and factors, several types of hedging rules have been developed.

In the one-point hedging (OPH) rule (Lund 1996), there is an optimal constant hedging factor, and when the available water is lower than the hedging volume, the water demand is reduced; otherwise, the full water demand can be drafted. Shih and ReVelle (1994) developed the discrete hedging (DH) rule. Using the DH rule, the dam operator can declare the water rationing stages to the public in a simple manner. Srinivasan and Philipose (1998) introduced the two-point hedging (TPH) rule in which water hedging is triggered when the available water is between the starting and ending water availability. Neelakantan and Sasireka (2013) developed the Binary SOP (BSOP) rule and the standard hedging (SH) rule to operate hydropower reservoirs. In the BSOP rule, the dam operator may store the currently available water in the reservoir for future use when the available water is lower than the optimal hedging volume. In the case of the SH rule, when the available water in the reservoir is low, the operation of fewer turbines with the full design discharge is considered instead of operating all turbines with the partial design discharge.

In general, several studies (Neelakantan and Sasireka 2013; Sasireka and Neelakantan 2016; Jin and Lee 2019; Tayebiyan et al. 2016, 2019; Felfelani et al. 2013; Chong et al. 2021) have used various hedging rules to operate hydropower reservoirs. However, these studies applied the concept of water rationing practice that uses the constant hedging factors at the current time without envisaging the future water use and demand. As a result, frequent power shortages are inevitable during the summer season, causing difficulties for dam operators to stabilize the power generation in the summer season.

Although numerous studies have applied different reservoir operation rules to the hydropower reservoirs, none have focused on improving summer power generation, which is crucial for hydropower dam operators. Thus, this study proposes the multi-step ahead TVH rule to improve summer power generation of a hydropower reservoir for the first time. In this study, the modified TVH rule was applied to avoid premature water spills. The results of the TVH rules were compared to those of the SOP rule, the BSOP rule, the SH rule, the $\mathrm{DH}$ rule, the OPH rule, and the TPH rule. This study is essential for the hydropower dam operators not only to gain knowledge of how to improve the power generation in the summer period but also to expand the knowledge of the diverse implications of different hedging rules.

In this paper, Sect. 2 expresses the study area. Section 3 presents the materials and methodology, and the results and discussion are provided in Sect. 4. The conclusion of the current work and suggestions are provided in Sect. 5.

\section{Study Area}

Myanmar has a tropical monsoon climate, mainly characterized by three seasons: the rainy season from June to October, the winter season from November to February, and the summer season from March to May.

The Yeywa Dam was constructed on the Myitnge River (also known as the Namtu River and the Dokhtawaddy River) in the Shan Plateau in central Myanmar. The catchment area at the Yeywa Dam site is $28026 \mathrm{~km}^{2}$. The total installed power of the Yeywa Power Plant is $790 \mathrm{MW}(4 \times 197.5 \mathrm{MW})$, and it is designed to generate 3,550 GWh per annum. The reservoir surface water area is $59 \mathrm{~km}^{2}$, and the tailwater level is taken as $78 \mathrm{~m}$. The normal high-water level (NHWL) and minimum water level (MWL) is $185 \mathrm{~m}$ and $148 \mathrm{~m}$, 
respectively. The total and active storage capacity of the Yeywa Dam is $2630 \mathrm{Mm}^{3}$ and $1680 \mathrm{Mm}^{3}$, respectively. The locations of the Yeywa Dam and the Yeywa Reservoir are shown in Fig. 1.

\section{Materials and Method}

\subsection{Materials}

The Yeywa Power Plant was commissioned in 2010, and it is owned by the Ministry of Electricity and Energy (MOEE), Myanmar. The required data, such as the monthly reservoir inflow, rainfall, water level, water demand, and the generated power data (2011-2016), were obtained from the MOEE.

Figure 2a shows the mean inflow and demand, and it can be noted that the mean inflow is lower than the mean demand in the winter and summer seasons. Figure $2 b$ shows the mean monthly evaporation and rainfall, and it can be seen that the evaporation rate peaks in the summer season; meanwhile, the available rainfall and reservoir inflow are low. Figure 2c expresses the reservoir storage-area-water level relationship curve of the Yeywa Reservoir (AF-Colenco 2009). Due to data limitations, the same mean monthly evaporation data obtained from a feasibility study report by KOEI (1999) is applied for the given study period (2011-2016). In Myanmar, frequent power shortages occur in the summer season due to the combination of high-power demand and low rainfall amounts. Therefore, generating stable or higher electric power in the summer season has become a major challenge for dam operators.

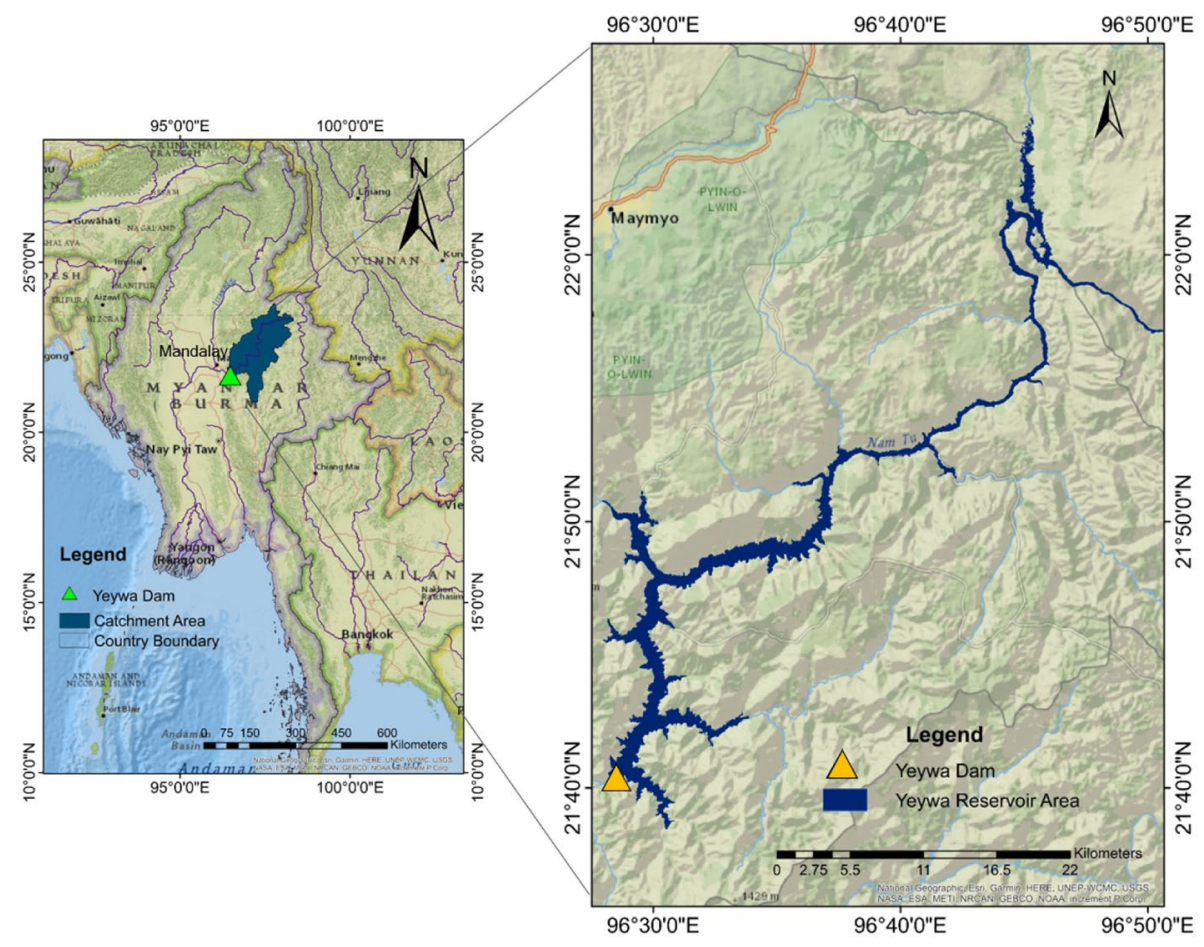

Fig. 1 Location map of the study area 

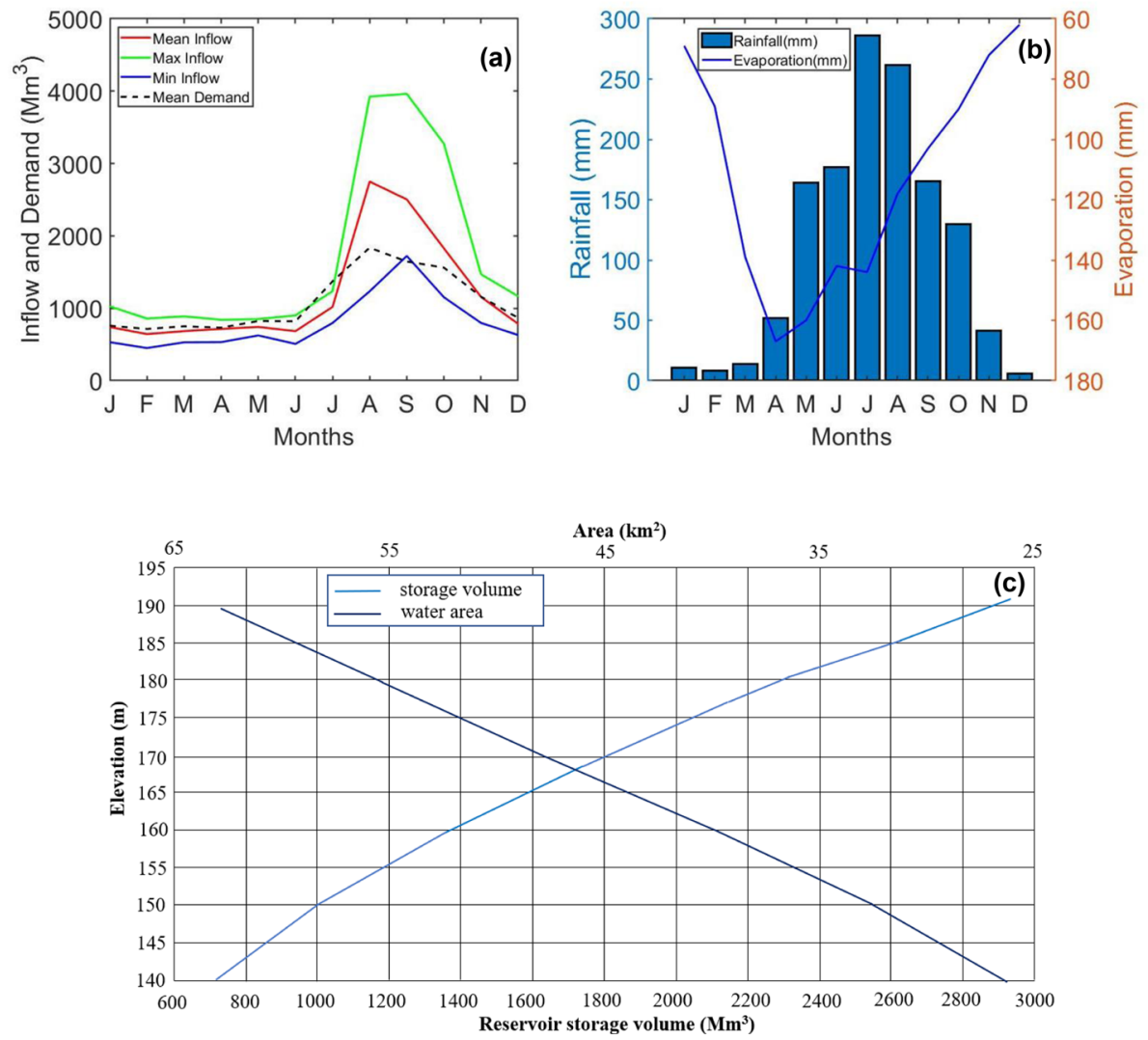

Fig. 2 (a) mean monthly inflow and demand, (b) mean monthly rainfall and evaporation, (c) reservoir storage- area-water level curves

\subsection{Methodology}

\subsubsection{Mathematical Representation of the Reservoir Simulation-Optimization Model}

Several studies have carried out reservoir optimization using different objective functions. This study used two objective functions: maximizing the total power generation (objective 1) and minimizing the average water deficit (objective 2) over the study period. In fact, the use of a single objective function to maximize power generation may conflict with the hedging rule practice because this objective function enforces the reservoir to release water as much as possible for maximum power generation while the hedging rule attempts to ration water. On the other hand, using a single objective function to minimize water shortage may decrease the water deficit, but power generation can be lower when the available water is higher than the demand. Thus, the two objective functions are formulated as follows:

$$
\operatorname{Max} E=\sum_{t=1}^{m} \eta \times \gamma \times R_{t} \times H N_{t} \times T
$$




$$
\operatorname{Min} S T=\sum_{t=1}^{m}\left|\frac{\left(D_{t}-R_{t}\right)}{\mathrm{m}}\right|
$$

where $E$ is the total energy generation over the study period $(\mathrm{kWh}), \eta$ is the efficiency of the hydropower plant, $\gamma$ is the specific weight of water $\left(\mathrm{kN} / \mathrm{m}^{3}\right), R_{t}$ is the released water at time $\mathrm{t}\left(\mathrm{Mm}^{3}\right), H N_{t}$ is the net head at time $\mathrm{t}(\mathrm{m}), \mathrm{m}$ is the length of the study period (months), $\mathrm{T}$ is the power generation period (hr), ST is the absolute averaged water shortage index $\left(\mathrm{Mm}^{3}\right)$ over the study period, and $D_{t}$ is the water demand at time $\mathrm{t}\left(\mathrm{Mm}^{3}\right)$. The following physical constraints were applied in this study:

$$
\begin{aligned}
& R_{\text {min }} \leq R_{t} \leq R_{\text {max }} \\
& S_{\text {min }} \leq S_{t} \leq S_{\text {max }}
\end{aligned}
$$

where $R_{\text {min }}$ is the minimum water release $\left(\mathrm{Mm}^{3}\right), R_{\max }$ is the maximum water release $\left(\mathrm{Mm}^{3}\right), S_{\text {min }}$ is the minimum reservoir water storage $\left(\mathrm{Mm}^{3}\right), S_{\max }$ is the maximum reservoir water storage $\left(\mathrm{Mm}^{3}\right)$, and $S_{t}$ is the reservoir water storage at time t $\left(\mathrm{Mm}^{3}\right)$.

The maximum and minimum water release was taken as $2217 \mathrm{Mm}^{3}$ and $0 \mathrm{Mm}^{3}$, respectively. The maximum and minimum storage capacity of the Yeywa Reservoir was taken as $2630 \mathrm{Mm}^{3}$ and $950 \mathrm{Mm}^{3}$, respectively. The efficiency of the power plant was taken as 0.89 according to the feasibility study report by AF-Colenco (2009), and T was taken as $24 \mathrm{hrs}$ $\times 30$ days/month. In this study, reservoir optimization was carried out based on a monthly time scale because the available data are monthly.

In the real-world reservoir operation, forecasting reservoir inflow is necessary to obtain the available water. However, this study aims to test the suitability of the TVH rule to improve the summer power generation of the Yeywa Reservoir. Thus, the perfect reservoir inflow forecast for the future time was used in this paper. This would eliminate those errors and uncertainties introduced by the imperfect information of reservoir inflow values over future time steps.

The required available water at time $t$ was calculated using the following equation:

$$
\begin{gathered}
W A_{t}=S_{t-1}+Q_{t}+r v_{t}-e v_{t}-D S \\
r v_{t}=r_{t} \times A_{t} \\
e v_{t}=e_{t} \times A_{t}
\end{gathered}
$$

where $W A_{t}$ is the available water at time $\mathrm{t}\left(\mathrm{Mm}^{3}\right), S_{t-1}$ is the reservoir water storage $\left(\mathrm{Mm}^{3}\right)$ at time $\mathrm{t}-1, Q_{t}$ is the reservoir inflow at time $\mathrm{t}\left(\mathrm{Mm}^{3}\right), r v_{t}$ is the rainfall volume at time $\mathrm{t}$ $\left(\mathrm{Mm}^{3}\right), e v_{t}$ is the evaporated water volume at time $\mathrm{t}\left(\mathrm{Mm}^{3}\right), r_{t}$ is the rainfall depth at time $\mathrm{t}$ $(\mathrm{m}), e_{t}$ is the evaporation depth at time $\mathrm{t}(\mathrm{m}), D S$ is the dead storage of the reservoir $\left(\mathrm{Mm}^{3}\right)$, and $A_{t}$ is the reservoir water area at time $\mathrm{t}\left(\mathrm{km}^{2}\right)$.

In this study, the initial reservoir storage was assumed to be full for all operating rules. The monthly rainfall volume was obtained by multiplying the rainfall depth by the reservoir area at time $t$ using the Eq. (6). The reservoir area at time $t$ was computed by interpolating from the reservoir area-storage capacity relationship (Fig. 2c). Similarly, the evaporated water volume was calculated by multiplying the evaporation depth by the reservoir surface area at time t using the Eq. (7). 
The water release and spill for the relevant rules were calculated using Eqs. (13) to (44). Then, the reservoir water storage at time $\mathrm{t}$ for all rules was calculated by subtracting the determined water release and spill using the Eq. (8). The water head was calculated using the calculated reservoir storage by interpolating the elevation-storage capacity relationship (Fig. 2c) for all rules. After that, the net water head for all rules was calculated by deducting the tailwater level (TWL) (m) from the average water head between $H_{t}(\mathrm{~m})$ and $H_{t-1}$ (m) using the Eq. (9).

$$
\begin{gathered}
S_{t}=S_{t-1}+Q_{t}+r v_{t}-e v_{t}-R_{t}-S P_{t} \\
H N_{t}=\frac{\left(H_{t}+H_{t-1}\right)}{2}-T W L
\end{gathered}
$$

where $S P_{t}$ is the water spill $\left(\mathrm{Mm}^{3}\right)$ at time t.

\subsubsection{Modified Multi-Step Ahead Time-Varying Hedging (TVH) Rule}

In real-world applications, the reservoir inflow and water demand may vary considerably over time. Therefore, using the constant hedging factors may not provide the most efficient reservoir performance as they may not capture the inflow and the water demand variability in detail. Meanwhile, the TVH rules can consider multi-step ahead water availability and water demand (termed herein 'future hydrological information') based on the specified period. Thus, the dam operator can proactively manage the reservoir operation to meet the power demand in the summer season.

In the TVH rules, three decision variables, $\left(\mathrm{x} 1, \mathrm{x} 2, \mathrm{HF}_{\mathrm{t}}\right)$ need to be optimized to obtain three hedging parameters, namely, the starting water availability for the $\mathrm{j}$ period at time $\mathrm{t}$ $\left(\mathrm{Mm}^{3}\right)\left(S W A_{t}^{j}\right)$, the ending water availability for the $\mathrm{j}$ period at time $\mathrm{t}\left(\mathrm{Mm}^{3}\right)\left(E W A_{t}^{j}\right)$, and the hedging factor $\left(\mathrm{HF}_{\mathrm{t}}\right)$, at time t. When the available water is higher than the $E W A_{t}^{j}$ and lower than the $S W A_{t}^{j}$, water hedging is not necessary. However, when the available water exists between the $S W A_{t}^{j}$ and $E W A_{t}^{j}$, water demand is reduced by a factor of $\mathrm{HF}_{\mathrm{t}}$.

To determine the $S W A_{t}^{j}$, the decision variable $x 1$ is taken as the coefficient of the total future water demand at time j-period, and it can be stated as $S W A_{t}^{j}=x 1 \times \sum_{i=1}^{j} D_{t+i-1}$. To obtain $E W A_{t}^{j}, x 2$ is taken as the coefficient of the active storage plus the total future water demand at time j-period, and it can be expressed as $E W A_{t}^{j}=\sum_{i=1}^{j} D_{t+i-1}+K \times x 2$. There is no coefficient for $\mathrm{HF}_{\mathrm{t}}$ because it indicates the percentage of water demand reduction between 0 and $100 \%$. The smaller $\mathrm{HF}_{\mathrm{t}}$ value means that higher water releasing is allowed, while the higher $\mathrm{HF}_{\mathrm{t}}$ value indicates that lower water releasing is permitted because $\mathrm{HF}_{\mathrm{t}}$ is subtracted from 1 and multiplied with the water demand to reduce water release. The range of all decision variables for the TVH rules is set from 0 to 1 .

The monthly time-varying hedging (TVH-1) rule, the quarterly time-varying hedging (TVH-3) rule, and the half-yearly time-varying hedging (TVH-6) rules are applied in this study. In the case of the TVH-1 rule, decision variables are optimized for every month, and there are 36 decision variables for a year (i.e., $3 \times 12$ ). The TVH-1 rule focuses on the monthly time scale, and it does not consider future hydrological information. However, in the case of the TVH-3 rule, the water availability and water demand for the three months (i.e., the current month and next two months) are accumulated and used to determine the water release and spill. The three decision variables are optimized for these three months to get the hedging thresholds and factors. In the TVH-3 rule, the decision variables are changed for every quarter; therefore, there are 12 decision variables for a year (i.e., $3 \times 4$ ). In the case of the TVH-6 
rule, hydrological information for six months (i.e., the current month and next five months) is accumulated and used for optimizing the decision variables to hedge water. Hence, there will be six decision variables for the TVH- 6 rule in a year (i.e., $3 \times 2$ ). The decision variables of the TVH rules are varied based on the specified j-period. This study does not use the timevarying hedging rule for a yearly period since the time scale is relatively coarse to capture the interannual river flow.

In this study, hydrological data and decision variables for the TVH rules were calculated starting from the beginning of the year based on the data availability. For instance, the TVH-1 rule calculates the decision variables for every month starting from January to December. The decision variables for the TVH-3 rule were defined for four quarters (i.e., January-March, April-June, July-September, and October-December). For the TVH-6 rule, two periods (i.e., January-June and July-December) were defined to calculate the decision variables. The sketch of the operation of the TVH rule is shown in Fig. 3.

In the TVH rule, an additional computation of the prior water availability and water demand at time $\mathrm{t}$ for the $\mathrm{j}$-period $\left(\sum_{i=1}^{j} D_{t+i-1}\right)\left(\mathrm{Mm}^{3}\right)$ is necessary if the $\mathrm{j}$-period is greater than one month. The following equations describe the calculation of water availability for the TVH rules.

$$
\begin{gathered}
W A_{t}^{j}=S_{t-1}+\sum_{i=1}^{j}\left(Q_{t+i-1}+r v_{t+i-1}-e v_{t+i-1}\right)-D S \\
r v_{t+i-1}=\sum_{i=1}^{j} r_{t+i-1} \times A_{t} \\
e v_{t+i-1}=\sum_{i=1}^{j} e_{t+i-1} \times A_{t}
\end{gathered}
$$

where $W A_{t}^{j}$ is the available water for the j-period at time $\mathrm{t}\left(\mathrm{Mm}^{3}\right), Q_{t+i-1}$ is the total reservoir inflow at the j-period $\left(\mathrm{Mm}^{3}\right), r v_{t+i-1}$ is the total rainfall volume for the j-period $\left(\mathrm{Mm}^{3}\right)$, $e v_{t+i-1}$ is the total evaporation volume for the j-period $\left(\mathrm{Mm}^{3}\right), r_{t+i-1}$ is the total rainfall depth at the j-period (m), and, $e_{t+i-1}$ is the total evaporation depth at the j-period (m). The water release and spill of the TVH rules can be computed using the following equations:

$$
\begin{gathered}
R_{t}=W A_{t} \quad S P_{t}=0 \quad W A_{t}^{j}<S W A_{t}^{j} \\
R_{t}=\left[S W A_{t}^{j}+\left(\left(1-H F_{t}\right) \times \sum_{i=1}^{j} D_{t+i-1}-S W A_{t}^{j}\right) \times \frac{\left(W A_{t}^{j}-S W A_{t}^{j}\right)}{\left(\sum_{i=1}^{j} D_{t+i-1}-S W A_{t}^{j}\right)}\right] \times\left(\frac{D_{t}}{\sum_{i=1}^{j} D_{t+i-1}}\right) \\
S P_{t}=0 \quad S W A_{t}^{j} \leq W A_{t}^{j}<\sum_{i=1}^{j} D_{t+i-1} \\
R_{t}=\left(1-H F_{t}\right) \times D_{t} \quad S P_{t}=0 \quad \sum_{i=1}^{j} D_{t+i-1} \leq W A_{t}^{j}<E W A_{t}^{j} \\
R_{t}=D_{t} \quad S P_{t}=0 \quad E A_{t}^{j} \leq W A_{t}^{j}<\sum_{i=1}^{j} D_{t+i-1}+K \\
R_{t}=D_{t} \quad S P_{t}=W A_{t}-R_{t}-K \quad \sum_{i=1}^{j} D_{t+i-1}+K \leq W A_{t}^{j}
\end{gathered}
$$




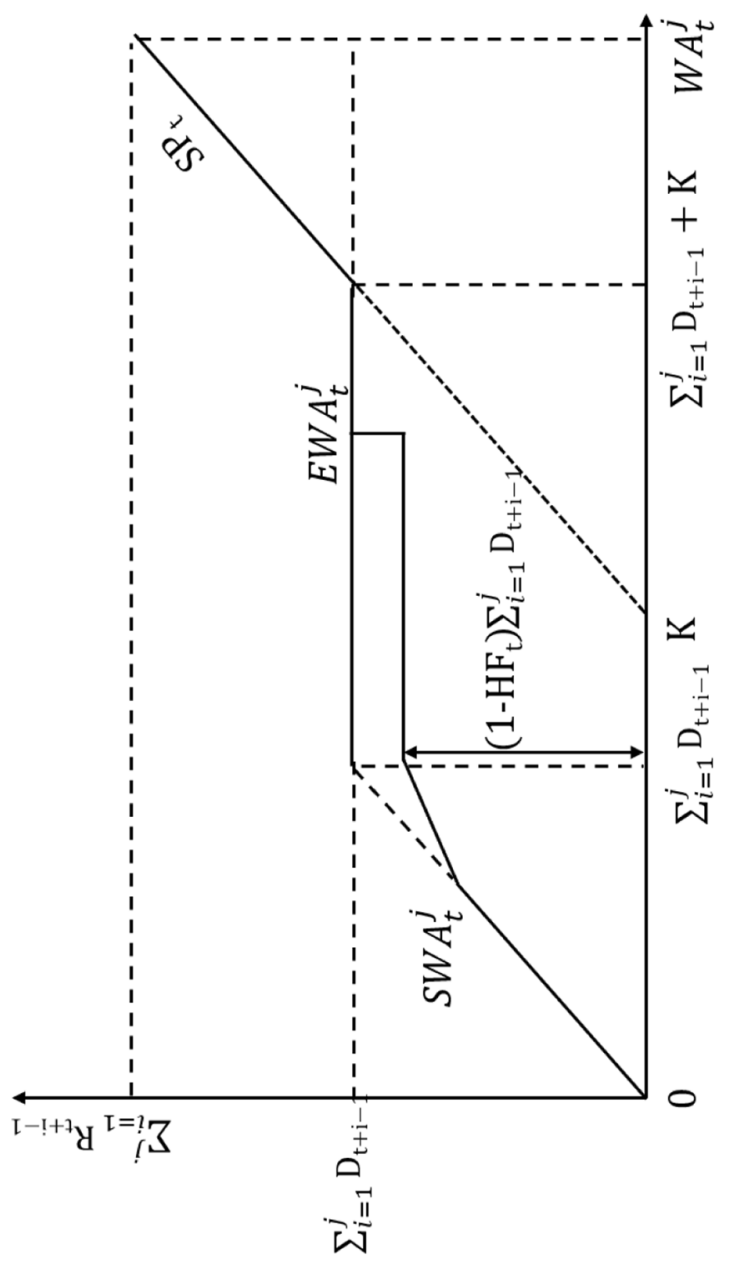

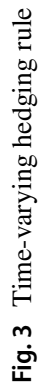


where $\mathrm{K}$ is the active reservoir storage capacity $\left(\mathrm{Mm}^{3}\right)$, and other variables were defined in the above sections.

The TVH rules require to apply both available water at the current time $\mathrm{t}\left(W A_{t}\right)$ and the available water for the j-period at time $\mathrm{t}\left(W A_{t}^{j}\right)$. In the case of the TVH-1 rule, water availability and demand are computed based on a monthly time scale to determine the water release. In the TVH-3 and TVH-6 rules, the values of $W A_{t}^{j}$ and $\sum_{i=1}^{j} D_{t+i-1}$ are computed to obtain the future hydrological information to calculate the water release and hedge water in advance. The water hedging states of the TVH-3 and TVH-6 rules rely on the conditions resulting from the future hydrological information. In the TVH rules, whenever the available water exists between $S W A_{t}^{j}$ and $E W A_{t}^{j}$, the current water demand at time $\mathrm{t}$ is rationed based on the defined hedging characteristics. Since it is impossible to store the future surplus water in the reservoir, water hedging is computed at the current time $t$ instead of the j-period (Shiau 2009).

Meanwhile, calculating the spill using the future hydrological information based on the original TVH rule concept can demand early water spill for the TVH-3 and TVH-6 rules. For instance, whenever the condition (i.e., $\sum_{i=1}^{j} D_{t+i-1}+K \leq W A_{t}^{j}$ ) in the Eq. (17) is satisfied, the reservoir water is enforced to spill prematurely at time t by subtracting the release and the active storage capacity from the current water availability at time $t$. This concept may work in the rainy season, but when the available water at time $t$ is low in the reservoir during the summer season, the spill values can be lower than zero, which is unfeasible in real-world conditions. As a result, the computation process will be ill-conditioned and terminated due to the negative spill values. Thus, if equations (13) to (16) are not satisfied, $\mathrm{R}_{\mathrm{t}}=\mathrm{D}_{\mathrm{t}}$, and spill calculation is modified as follows:

$$
R_{t}=D_{t} \quad S P_{t}=W A_{t}-R_{t}-K \quad W A_{t}-D_{t}>K
$$

The implication is that the future hydrological information is used in the TVH rules for the benefits of water hedging in advance only, and computation of spill in the TVH rules is considered based on the current hydrological information like the other rules.

\subsubsection{Standard Operation Policy (SOP) Rule}

In the SOP rule (Fig. 4a), the available water is released if it is less than the water demand; otherwise, the target water demand is released. The SOP rule can be computed using the following equations.

$$
\begin{gathered}
R_{t}=W A_{t} \quad S P_{t}=0 \quad W A_{t}<D_{t} \\
R_{t}=D_{t} \quad S P_{t}=0 \quad D_{t} \leq W A_{t}<D_{t}+K \\
R_{t}=D_{t} \quad S P_{t}=W A_{t}-R_{t}-K \quad D_{t}+K \leq W A_{t}
\end{gathered}
$$

\subsubsection{Binary Standard Operation Policy (BSOP) Rule}

The water hedging practice of the BSOP rule (Fig. 4b) is like the SOP rule, except the BSOP rule stops water releasing when the available water is lower than the hedging volume, $B\left(\mathrm{Mm}^{3}\right)$. $B$ is calculated by multiplying it by the active storage capacity, $K$ (i.e., $B \times$ 


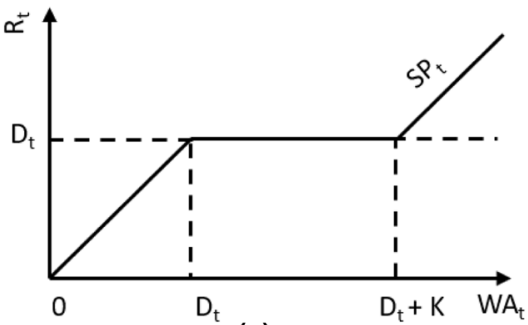

(a)

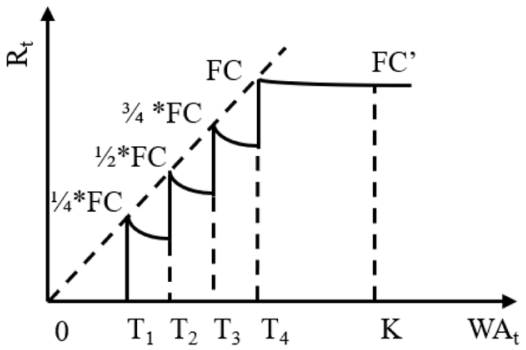

(c)

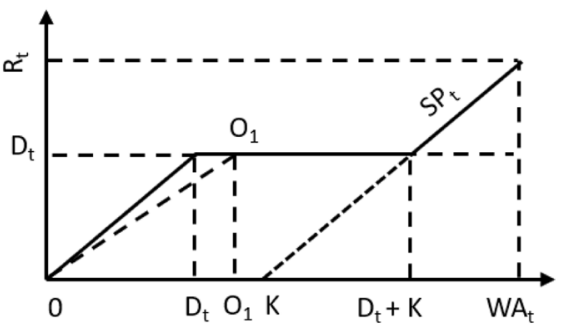

(e)

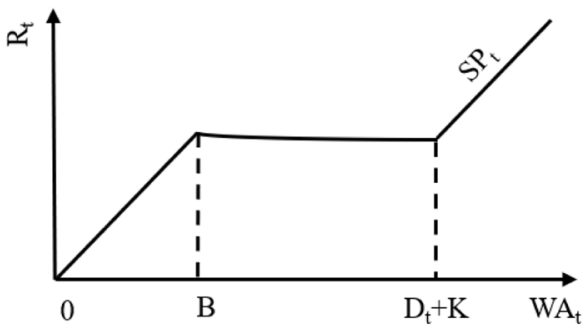

(b)

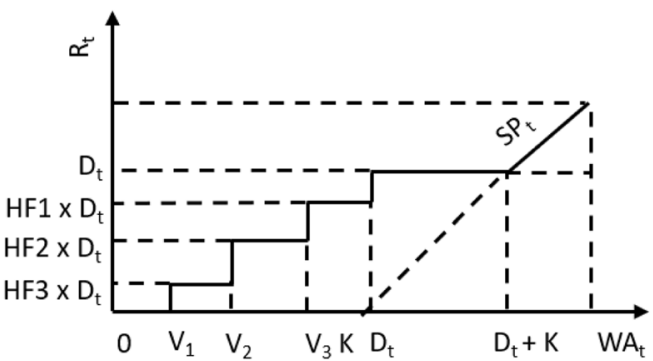

(d)

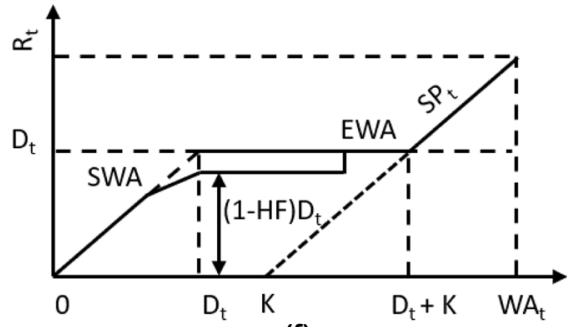

(f)

Fig. 4 (a) the SOP rule (b) the BSOP rule (c) the SH rule (d) the DH rule (e) the OPH rule (f) the TPH rule

$K$ ) (Tayebiyan et al. 2016). The $B$ value ranges from 0 to 1 , and the BSOP rule can be computed using the following equations.

$$
\begin{gathered}
R_{t}=0 \quad S P_{t}=0 \quad W A_{t}<B \\
R_{t}=D_{t} \quad S P_{t}=0 \quad B \leq W A_{t}<D_{t}+K \\
R_{t}=D_{t} \quad S P_{t}=W A_{t}-R_{t}-K \quad D_{t}+K \leq W A_{t}
\end{gathered}
$$

\subsubsection{Standard Hedging (SH) Rule}

The SH rule (Fig. 4c) hedges water based on the water availability corresponding to the installed turbine numbers. In detail, if the available water in the reservoir is low, the reservoir is operated running the fewer turbines with full capacity of design discharge $(F C)$ instead of operating all turbines with partial design discharge (Neelakantan and Sasireka 2013). 
In a hydropower plant with four turbines in the same power generation capacity, each turbine will generate $25 \%$ of the total installed power capacity. Since the Yeywa power plant has four turbines, there are four optimal hedging volumes such as, $T_{1}, T_{2}, T_{3}$, and $T_{4}$. They were calculated by multiplying them by $F C$, and it can be stated as, $T_{1} \times F C, T_{2} \times F C, T_{3} \times F C$ and $T_{4} \times F C$, respectively. The hedging volumes range between 0 to 1 , they are conditioned as $T 1 \leq T 2 \leq T 3 \leq T 4$. Since the values of $T_{1}, T_{2}, T_{3}$, and $T_{4}$ are obtained, water release for each turbine can be calculated using the following equations.

$$
\begin{array}{ccc}
R_{t}=0 & S P_{t}=0 & W A_{t}<T_{1} \\
R_{t}=0.25 \times F C & S P_{t}=0 & T_{1}<W A_{t}<T_{2} \\
R_{t}=0.5 \times F C & S P_{t}=0 & T_{2}<W A_{t}<T_{3} \\
R_{t}=0.75 \times F C & S P_{t}=0 & T_{3}<W A_{t}<T_{4} \\
R_{t}=1 \times F C & S P_{t}=0 & T_{4}<W A_{t}<K \\
R_{t}=1 \times F C & S P_{t}=W A_{t}-K & W A_{t}>K
\end{array}
$$

where $\mathrm{K}$ is the full reservoir capacity $\left(\mathrm{Mm}^{3}\right)$ in this rule.

\subsubsection{Discrete Hedging (DH) Rule}

In the DH rule (Fig. 4d), the target water demand is rationed by multiplying it by the hedging factors for each hedging phase. Since three hedging phases were considered in this study, and there were three hedging volumes such as, $V_{1}, V_{2}$, and $V_{3}$. These three hedging volumes were obtained by multiplying them with the active storage capacity $(K)$. It can be noted as $V_{1} \times K, V_{2} \times K$ and $V_{3} \times K$. Meanwhile, three hedging factors $H F_{3}, H F_{2}, H F_{1}$ were calculated by multiplying them by the demand. It can be expressed as $H F_{1} \times D_{t}$, $H F_{2} \times D_{t}$ and $H F_{3} \times D_{t}$. The hedging volumes and factors are conditioned as $V_{1} \leq V_{2} \leq V_{3}$ and $H F_{3} \leq H F_{2} \leq H F_{1}$ and their values range between 0 to 1 . The operation of the $\mathrm{DH}$ rule is computed as follows:

$$
\begin{gathered}
R_{t}=0 \quad S P_{t}=0 \quad W A_{t}<V_{1} \\
R_{t}=H F_{3} \times D_{t} \quad S P_{t}=0 \quad V_{1} \leq W A_{t}<V_{2} \\
R_{t}=H F_{2} \times D_{t} \quad S P_{t}=0 \quad V_{2} \leq W A_{t}<V_{3} \\
R_{t}=H F_{1} \times D_{t} \quad S P_{t}=0 \quad V_{3} \leq W A_{t}<D_{t} \\
R_{t}=D_{t} \quad S P_{t}=0 \quad D_{t} \leq W A_{t}<D_{t}+K \\
R_{t}=D_{t} \quad S P_{t}=W A_{t}-R_{t}-K \quad W A_{t} \geq D_{t}+\mathrm{K}
\end{gathered}
$$




\subsubsection{One-Point Hedging (OPH) Rule}

In the $\mathrm{OPH}$ rule (Fig. 4e), there is only one hedging point to ration water. A water hedging volume, $O_{1}\left(\mathrm{Mm}^{3}\right)$, is determined by multiplying it by the active storage capacity $(K)$, and it can be stated as $O_{1} \times K$ (Tayebiyan et al., 2019). The value of $O_{1}$ ranges from 0 to 1 , and the operation of the $\mathrm{OPH}$ rule is computed as follows.

$$
\begin{gathered}
R_{t}=\left[\frac{W A_{t}}{O_{1}}\right] \times D_{t} \quad S P_{t}=0 \quad W A_{t}<O_{1} \\
R_{t}=D_{t} \quad S P_{t}=0 \quad O_{1} \leq W A_{t}<D_{t}+K \\
R_{t}=D_{t} \quad S P_{t}=W A_{t}-R_{t}-K \quad W A_{t} \geq D_{t}+K
\end{gathered}
$$

\subsubsection{Two-Point Hedging (TPH) Rule}

Like the TVH rule, there are three hedging parameters in the TPH rule (Fig. 4f), namely, the starting water availability at time $\mathrm{t}\left(S W A_{t}\right)\left(\mathrm{Mm}^{3}\right)$, the ending water availability at time $\mathrm{t}\left(E W A_{t}\right)\left(\mathrm{Mm}^{3}\right)$, and the hedging factor (HF) (Srinivasan and Philipose 1998). The $S W A_{t}$ values vary from 0 to $D_{t}$, and the $E W A_{t}$ values range between $D_{t}$ and $D_{t}+K$, where; $K$ is the active reservoir storage. There are three decision variables $(p 1, p 2, H F)$ to be optimized in this rule. The $S W A_{t}$ is calculated by multiplying the water demand by $p 1$ and it can be stated as $p 1 \times D_{t}$. The $E W A_{t}$ is calculated by adding the water demand and the active storage capacity $(\mathrm{K})$ times $p 2$, and it can be expressed as $D_{t}+K \times p 2$. Similar to the TVH rule, the decision variable HF has no coefficients. All decision variables range between 0 to 1 , and the TPH rule operation can be expressed as follows.

$$
\begin{aligned}
& R_{t}=W A_{t} \quad S P_{t}=0 \quad W A_{t}<S W A_{t} \\
& R_{t}=S W A_{t}+\left[(1-H F) \times D_{t}-S W A_{t}\right] \times\left[\frac{W A_{t}-S W A_{t}}{D_{t}-S W A_{t}}\right] \\
& S P_{t}=0 \\
& S W A_{t} \leq W A_{t}<D_{t} \\
& R_{t}=(1-H F) \times D_{t} \quad S P_{t}=0 \quad D_{t} \leq W A_{t}<E W A_{t} \\
& R_{t}=D_{t} \quad S P_{t}=0 \quad E W A_{t} \leq W A_{t}<D_{t}+K \\
& R_{t}=D_{t} \quad S P_{t}=W A_{t}-R_{t}-K \quad D_{t}+K \leq W A_{t}
\end{aligned}
$$

\subsection{Optimization Method}

This study applied the Multi-Objective Genetic Algorithm (MOGA), gamulti-obj function, in Matlab. The MOGA is a variant of Non-Dominated Sorting Genetic Algorithm-II (NSGA-II), developed by Deb (2001). The operation of the MOGA involves the following steps: initializing the population within the specified boundaries, evaluating the fitness 
function, selecting parents for the next generation, creating children using the genetic operator such as crossover, and mutation, computing the rank and using the crowding distance calculation. The process is repeated for the defined number of generations to get the nondominated Pareto optimal solutions. The MOGA uses elitism to improve the diversity of the population through generations for preserving the best fitness solutions. More information about the concepts of MOGA can be available in (MathWorks 2021; Deb 2001).

The present study applied the two-point crossover method since it provides better results than other crossover techniques (Hakimi et al. 2016). The default tournament selection and mutationadaptfeasible methods are applied. To obtain the suitable MOGA parameters, analysing the sensitivity of parameters (population size, crossover, and the number of generations) is carried out by performing several independent runs with the TVH-1 rule, which has the highest number of decision variables amongst all operating rules. Different population sizes $(50,100,200,300,400)$, crossover values $(0.6,0.7,0.8$ and 0.9$)$ and different number of generations $(100,200,500,700$, and 1000) were analysed in the present study. It was found that when the crossover value is 0.9 , the population size is 300 , and the generation time is 500 times, the MOGA provides the highest performance for two objective functions. The maximum computation time for a single run is $1027 \mathrm{~s}$. Further increase in the population size above 300 and the generation numbers higher than 500 times does not give better solutions; however, the computational time has increased significantly. To ensure reaching the global optimum, a population size of 300, the crossover value of 0.9 , and 1000 number of generations were applied for all hedging rules. All the simulations were performed on a computer containing dual Intel (R) Core (TM) i5 CPUs with $2.7 \mathrm{GHz}$ and 16.0 GB RAM.

After selecting the parameters, the input data such as monthly rainfall, evaporation, reservoir inflow, water demand data were imported to the model. Then, the MOGA began by randomly generating the decision variables to be optimized. The decision variables and their coefficients for each operating rule are expressed in Table 1. Since the SOP rule is a simple reservoir operating rule, it has no parameters to be optimized. After setting the decision variables, they were evaluated using the objective functions. The MOGA optimizes the decision variables until the solution reaches the convergence criteria.

\section{Results and Discussion}

Figure 5 showed that all hedging rules generated the Pareto fronts with multiple solutions, except the BSOP rule. It may be regarded that there were no alternative optimal solutions for the BSOP rule, and the two objective functions reached the same global optimum. Since this study aims to improve the summer power, the Pareto Optimal that can generate the highest summer power generation (termed herein "the optimal summer power") was selected from each Pareto front.

The total power generation of each rule between 2011 to 2016 are shown in Table 2. In contrast, the total power generation of the Yeywa Reservoir by the Electric Power Generating Enterprise (EPGE) was lower than those of the other rules. The current operation practice of the Yeywa Reservoir is called the EPGE rule.

Based on the results, the TVH rules outperformed other rules in total power generation. The TVH-6 rule generated the highest total electrical energy among all operating rules, followed by the TVH-3 rule, THV-1 rule, TPH rule, DH rule, the BSOP rule, and the OPH rule. Meanwhile, the $\mathrm{SH}$ rule generated the least total electrical energy among all hedging 
Table 1 Hedging thresholds and total numbers of decision variables (2011-2016) for each hedging rule

\begin{tabular}{|c|c|c|c|c|c|c|}
\hline \multirow[t]{2}{*}{ Rules } & \multirow{2}{*}{$\begin{array}{l}\text { Decision variables and } \\
\text { coefficients }\end{array}$} & \multirow{2}{*}{$\begin{array}{l}\text { Hedging } \\
\text { thresholds }\end{array}$} & \multicolumn{2}{|c|}{ Boundary } & \multirow[t]{2}{*}{ Constraints } & \multirow{2}{*}{$\begin{array}{l}\text { Total } \\
\text { decision } \\
\text { variables }\end{array}$} \\
\hline & & & Lower & Upper & & \\
\hline \multirow[t]{2}{*}{ BSOP } & $B \times K$ & $B$ & 0 & 1 & & 1 \\
\hline & $T_{1} \times F C$ & $T_{1}$ & 0 & 1 & & \\
\hline \multirow[t]{5}{*}{$\mathrm{SH}$} & $T_{2} \times F C$ & $T_{2}$ & 0 & 1 & $T 1 \leq T 2 \leq T 3 \leq T 4$ & 4 \\
\hline & $T_{3} \times F C$ & $T_{3}$ & 0 & 1 & & \\
\hline & $T_{4} \times F C$ & $T_{4}$ & 0 & 1 & & \\
\hline & $V_{1} \times K$ & $V_{1}$ & 0 & 1 & & \\
\hline & $V_{2} \times K$ & $V_{2}$ & 0 & 1 & & \\
\hline \multirow[t]{4}{*}{ DH } & $V_{3} \times K$ & $V_{3}$ & 0 & 1 & $V_{1} \leq V_{2} \leq V_{3}$ & 6 \\
\hline & $H F_{1} \times D_{t}$ & $H F_{1}$ & 0 & 1 & $H F_{1} \leq H F_{2} \leq H F_{3}$ & \\
\hline & $H F_{2} \times D_{t}$ & $H F_{2}$ & 0 & 1 & & \\
\hline & $H F_{3} \times D_{t}$ & $H F_{3}$ & 0 & 1 & & \\
\hline \multirow[t]{2}{*}{$\mathrm{OPH}$} & $O_{1} \times K$ & $O_{1}$ & 0 & 1 & & 1 \\
\hline & $p 1 \times D_{t}$ & $S W A_{t}$ & 0 & 1 & & \\
\hline \multirow[t]{3}{*}{ TPH } & $D_{t}+K \times p 2$ & $E W A_{t}$ & 0 & 1 & & 3 \\
\hline & - & $H F$ & 0 & 1 & & \\
\hline & $x 1 \times \sum_{i=1}^{j} D_{t+i-1}$ & $S W A_{t}^{j}$ & 0 & 1 & & $216^{*}$ \\
\hline \multirow[t]{2}{*}{ TVH } & $\sum_{i=1}^{j} D_{t+i-1}+K \times x 2$ & $E W A_{t}^{j}$ & 0 & 1 & & $72^{* *}$ \\
\hline & - & $H F_{t}$ & 0 & 1 & & $36^{* * *}$ \\
\hline
\end{tabular}

Note ${ }^{*},{ }^{* *},{ }^{* * *}$ refers to the total decision variables for the TVH-1 rule, TVH-3 rule, and the TVH- 6 rule, respectively

rules followed by the SOP rule. In real-world condition, the Yeywa Reservoir operation focuses on supporting the summer energy needs instead of maximizing the power generation throughout the year. Therefore, the total generated electricity of the Yeywa power plant was lower than those of the other rules.

In the case of the seasonal power generation (Table 3), the summer power generation of the TVH rules was higher than those of the other rules. This is because the TVH rules can trigger water hedging in advance due to the use of future hydrological information. In fact, the reservoir may have enough water at the current time, and it can release full water demand. However, due to the prior water hedging practices of the TVH rules, water is hedged and stored in the reservoir prior to the summer season. Since the rainy and the winter seasons come before the summer season, water hedging can be triggered in those seasons. Then, the stored water in the reservoir can be used in the summer season resulting in higher summer power generation than the other rules. Meanwhile, the TVH-1 rule does not use future hydrological information, but it generates high summer power. One of the reasons is that the TVH-1 rule uses monthly hedging parameters so that water is optimally released every month, resulting in high summer power generation. At the same time, the TVH rules generated less power generation in the winter season than the other rules, as these rules might hedge water in the winter season.

In the case of the $\mathrm{SH}$ rule, it generated the lowest power generation in the summer and the winter seasons compared to the other rules. It is due to the fact that the hedging practice of the $\mathrm{SH}$ rule depends on the water availability of the turbine numbers that 

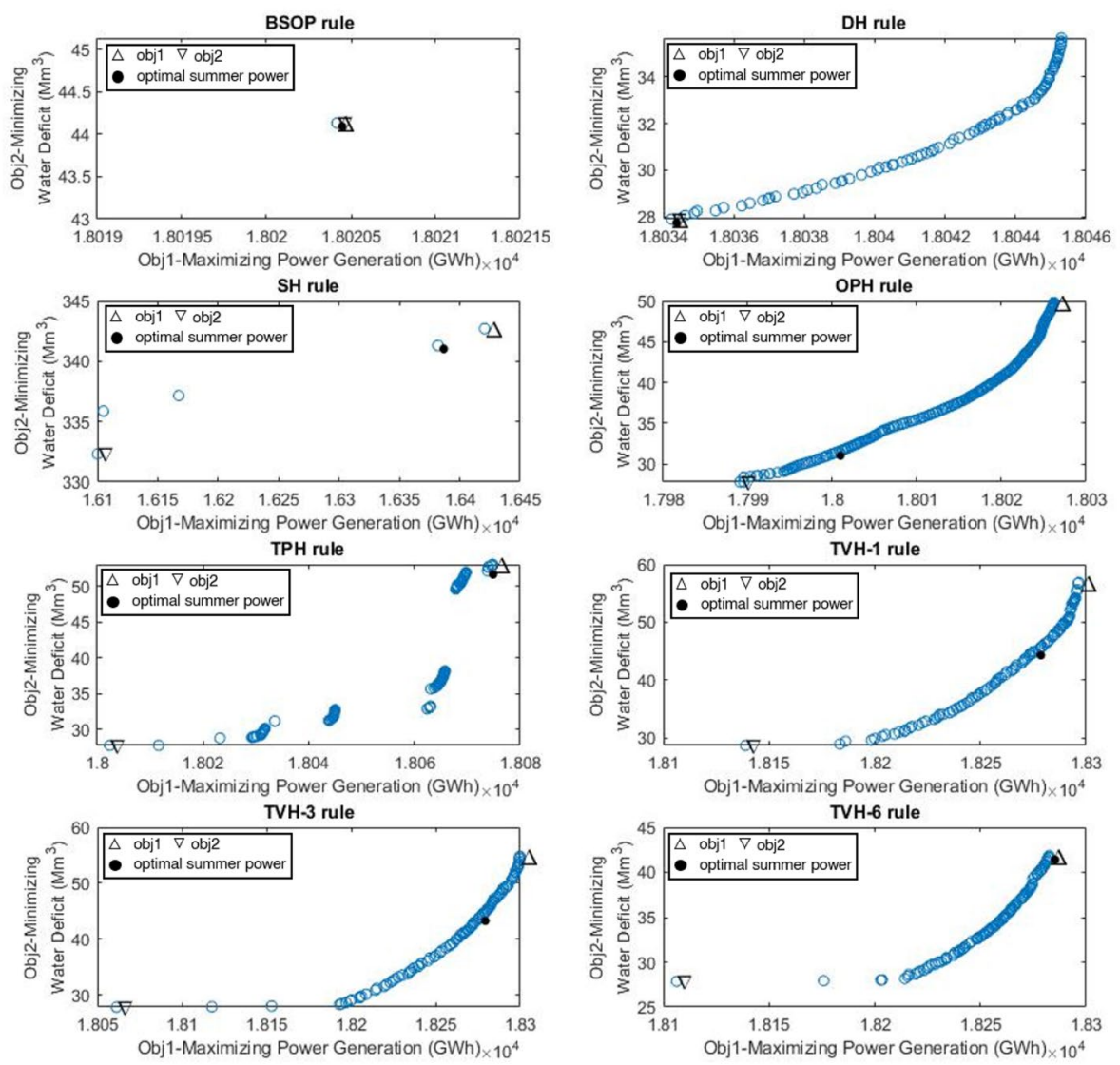

Fig. 5 Pareto fronts for hedging rules

can run with full designed discharge capacity. Thus, the SH rule runs a few turbines in full discharge capacity when the inflow is low in the summer and the winter seasons. On the other hand, the $\mathrm{SH}$ rule generated more electric power by running all turbines in

Table 2 Comparison of the total generated power (GWh) between 2011-2016

\begin{tabular}{llll}
\hline $\begin{array}{l}\text { Operating } \\
\text { Rules }\end{array}$ & $\begin{array}{l}\text { Total Power } \\
(\mathrm{GWh})\end{array}$ & $\begin{array}{l}\text { Improved Power } \\
(\mathrm{GWh})\end{array}$ & $\begin{array}{l}\text { Improved Power } \\
(\%)\end{array}$ \\
\hline EPGE & $15,120.22$ & & \\
SOP & $17,989.07$ & 2868.85 & 18.97 \\
BSOP & $18,020.42$ & 2900.20 & 19.18 \\
DH & $18,034.08$ & 2913.86 & 19.27 \\
SH & $16,381.87$ & 1261.65 & 8.34 \\
OPH & $18,000.32$ & 2880.10 & 19.05 \\
TPH & $18,073.83$ & 2953.61 & 19.53 \\
TVH-1 & $18,275.92$ & 3155.70 & 20.87 \\
TVH-3 & $18,276.18$ & 3155.96 & 20.87 \\
TVH-6 & $18,282.49$ & 3162.27 & 20.91 \\
\hline
\end{tabular}


Table 3 Comparison of the seasonal generated power (GWh) between 2011-2016

\begin{tabular}{|c|c|c|c|c|c|c|}
\hline $\begin{array}{l}\text { Operating } \\
\text { Rules }\end{array}$ & $\begin{array}{l}\text { Summer } \\
\text { (MAM) }\end{array}$ & $\begin{array}{l}\text { Difference } \\
(\%)\end{array}$ & $\begin{array}{l}\text { Rainy } \\
\text { (JJASO) }\end{array}$ & $\begin{array}{l}\text { Difference } \\
(\%)\end{array}$ & $\begin{array}{l}\text { Winter } \\
\text { (NDJ) }\end{array}$ & $\begin{array}{l}\text { Difference } \\
(\%)\end{array}$ \\
\hline EPGE & 2884.62 & & 7162.53 & & 5073.07 & \\
\hline SOP & 2649.55 & -8.15 & $10,105.16$ & 41.08 & 5234.36 & 3.18 \\
\hline BSOP & 2535.35 & -12.11 & $10,250.71$ & 43.12 & 5234.36 & 3.18 \\
\hline $\mathrm{DH}$ & 2596.21 & -10.00 & $10,203.51$ & 42.46 & 5234.36 & 3.18 \\
\hline SH & 1869.77 & -35.18 & $10,441.06$ & 45.77 & 4071.04 & -19.75 \\
\hline $\mathrm{OPH}$ & 2651.67 & -8.08 & $10,122.49$ & 41.33 & 5226.17 & 3.02 \\
\hline ТPH & 2753.67 & -4.54 & $10,227.22$ & 42.79 & 5092.93 & 0.39 \\
\hline TVH-1 & 3176.11 & 10.11 & $10,459.60$ & 46.03 & 4640.21 & -8.53 \\
\hline TVH-3 & 3015.00 & 4.52 & $10,449.29$ & 45.89 & 4811.89 & -5.15 \\
\hline TVH-6 & 3206.67 & 11.16 & $10,364.96$ & 44.71 & 4710.87 & -7.14 \\
\hline
\end{tabular}

full discharge capacity when the available water is high in the rainy season. In contrast, the SOP rule, the BSOP rule, the DH rule, the OPH rule, and the TPH rule generated electricity lower in the summer season and higher in the winter season compared to the TVH rules. This is because these rules do not have the capability of prior water hedging practice and hedging factors like theTVH rules; therefore, they cannot efficiently mitigate the negative impacts of summer droughts.

Figure 6a shows the monthly power generation pattern of all rules, and it can be seen from the figure that the power generation of the SH rule was flat in the winter and summer seasons. This is due to the fact that the $\mathrm{SH}$ rule runs the similar number of fewer turbines in full discharge capacity when the available water is low in the winter and summer seasons, and it stops power generation if the available water is not adequate to run a turbine. In the case of the BSOP and the DH rules, power generation was stopped when the water availability was lower than the optimal hedging thresholds. Therefore, there were less or no power generation for the $\mathrm{SH}$, BSOP, and $\mathrm{DH}$ rules in the summer months. The power generation patterns of the SOP and the OPH rules are similar except in the summer season when the OPH rule hedges water. The power generation pattern of the TPH rule was higher than those of the SOP and the OPH rules in the summer season. It can be explained that the TPH rule may hedge water in the rainy and winter season when the available water is higher than the demand and lower than the $E W A_{t}$. Then, the hedged water can be used in the summer season resulting in higher power than the SOP and OPH rules. Meanwhile, the TVH-3 and the TVH-6 rules had higher power generation patterns than the other rules in the summer season due to prior water hedging practice. However, the TVH-1 rule had sharp dips in power generation during some summer months because it cannot hedge water in advance like the TVH-3 and the TVH-6 rules.

The monthly reservoir water levels of different rules are shown in Fig. 6b. The water level of the SH rule was different from those of the other rules. As mentioned above, the $\mathrm{SH}$ rule operates the reservoir based on the availability of full designed discharge capacity for each turbine. Meanwhile, the other rules run the reservoir considering the demand; thus, the water levels of those rules were different. Since the SH rule does not allow water to release when the inflow is insufficient to run at least one turbine, some amount of water capacity is stored in the reservoir, and the water level does not reach the MWL. 

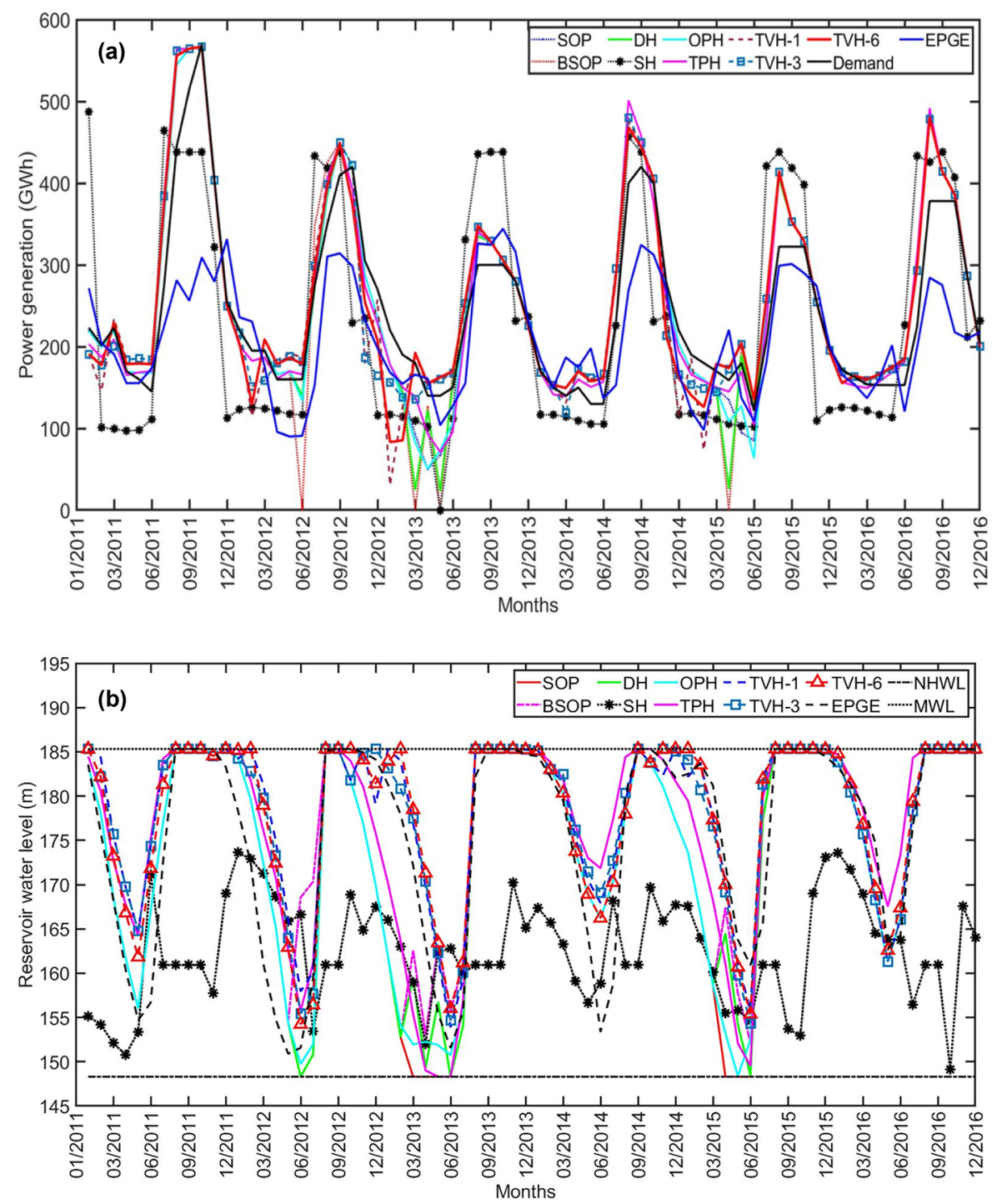

Fig. 6 (a) monthly power generation (b) monthly reservoir water level

In the case of the SOP rule, the water level reached the MWL in the summer months for 2012, 2013, and 2015 because it released all available water when the water availability was lower than the demand. The water levels of the DH rule, OPH rule, and TPH rule were also close to the MWL; however, they did not reach the MWL as prolonged as the SOP rule does due to their water hedging practices.

In contrast, the water levels of the TVH rules were close to the NHWL and higher than those of the other rules in the summer months. It is due to the fact that the TVH rules rationed water in the rainy and winter months, reducing water release. As a result, the hedged water is stored in the reservoir, and it is used in the summer period, leading to higher water level than the other rules in the summer season. Since the reservoir storage 
and water level are directly related, this paper did not give a separate discussion of the reservoir storage.

To evaluate the performance of different reservoir operation rules based on their capability on power generation, four criteria, namely, reliability, resilience, vulnerability (Hashimoto et al. 1982), and sustainability index, were utilized.

The reservoir reliability index $(\alpha)$ is defined as the probability that the reservoir will supply the energy demand; the higher $\alpha$ value means the reservoir is more reliable to generate the required energy demand. The $\alpha$ value ranges between 0 and 1, and it can be computed as follow:

$$
\alpha=\frac{S_{r}}{m} \quad, 0<\alpha<1
$$

where $S_{r}$ is the number of months that the reservoir can successfully meet the power demand, and $m$ is the total number of months.

Resilience $(\beta)$ is a performance indicator of how quickly the reservoir operating systems can rebound if there has been a failure and the higher value means the system has high resiliency. The $\beta$ value range between 0 and 1 , and it can be calculated as follows:

$$
\beta=\frac{f_{s}}{f t} \quad, f t \neq 0 \quad, 0<\beta<1
$$

where $f_{s}$ is the number of separate continuous failure periods; $f t$ is the number of total failure times.

Vulnerability $\left(v^{\prime}\right)$ indicates the severity of system failures, and it can be computed as follows:

$$
v^{\prime}=\frac{\sum_{k=1}^{f s} \max \left(E_{s}\right)}{f s}
$$

where $E_{s}$ is the energy shortage in each continuous failure period, and $f s$ is the number of separate continuous failure periods.

The maximum energy shortage, $E_{s}$ has a unit in GWh while $f s$ has no unit. Thus, the value of $v^{\prime}$ is divided by the target energy demand $\left(E_{d}\right)(\mathrm{GWh})$, corresponding to the same month where the maximum energy deficit $\left(E_{s}\right)$ is obtained. This value is called the dimensionless form of vulnerability ( $v$ ) (McMahon et al. 2006), and it can be calculated as follows:

$$
v=\frac{v^{\prime}}{E_{d}} \quad, 0<v<1
$$

The value of $v$ ranges from 0 and 1 , and the high value indicates that the system is highly vulnerable. More information on the reservoir performance indices calculation is available in the literature by McMahon et al. (2006).

To measure how the system is sustainable, the sustainability $(\Omega)$ index (Loucks 1997$)$ is computed using the following equation:

$$
\Omega=\alpha \times \beta \times(1-v) \quad, 0<v<1
$$

The value of $\Omega$ ranges from 0 to 1 , and 0 means the worst, and 1 represents the best.

Figure 7 showed the performance indices of different rules, and it can be seen that the reliability of the TVH rules was higher than those of the other rules; meanwhile, the 


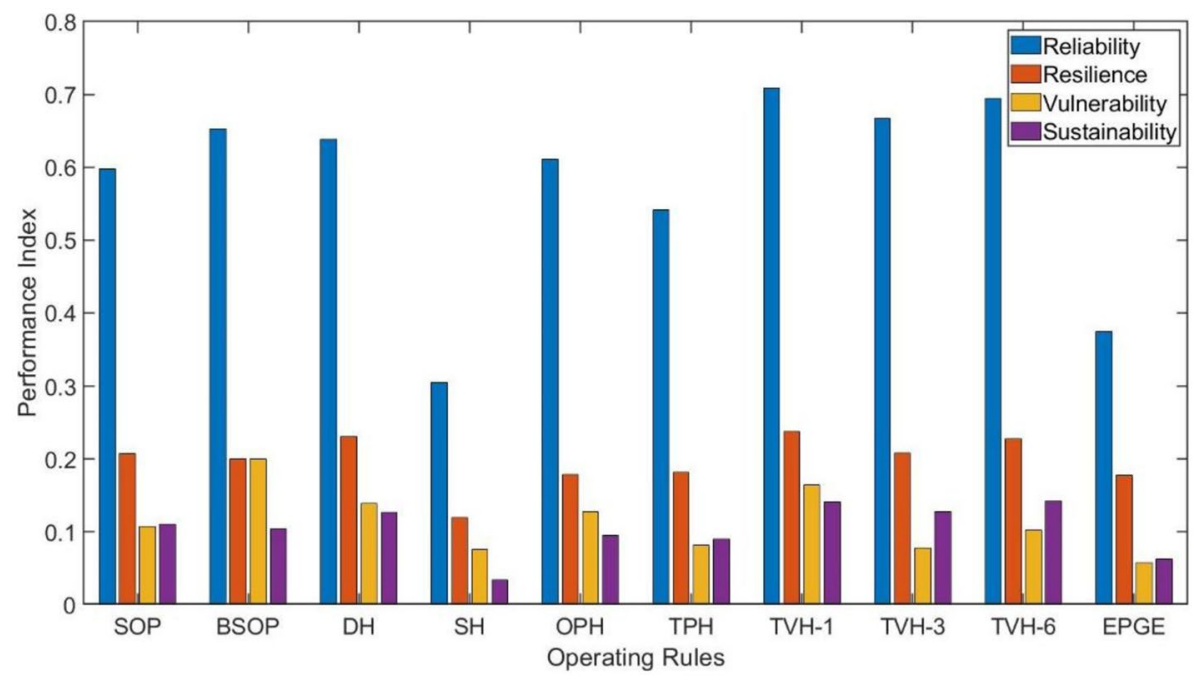

Fig. 7 Performance indices of the reservoir operating rules

TVH-1 rule was the highest, and the SH rule was the lowest reliable rule. In terms of resiliency, the TVH rules were more resilient compared to the other rules. The TVH-1 rule had the highest resiliency, and the lowest resilient rule was the EPGE rule. Meanwhile, the BSOP rule was the highest vulnerable rule, and the current EPGE rule was the least vulnerable one. The TVH-3 and the TVH-6 rules had low vulnerability; however, the TVH-1 rule had the second-highest vulnerability. In the case of sustainability, the TVH rules had higher sustainability than the other rules, and the TVH-6 rule was the most sustainable rule, and the least sustainable rule was the $\mathrm{SH}$ rule.

In general, the TVH rules had higher reservoir performance than the other rules. The TVH-6 rule had the highest sustainability index with high reliability, resiliency, and moderate vulnerability compared to the other rules. In addition, the TVH-6 rule generated higher summer power and total power than other rules. Thus, it can be noted that the TVH-6 rule is a promising rule to improve the summer power generation of the Yeywa Reservoir.

\section{Conclusions}

This paper proposed the use of the modified TVH rules for improving summer power generation. The TVH rule considers the multi-step ahead hydrological information to ration water in advance, and thus the hedged water can be used in the summer period. The developed reservoir simulation-optimization model was used in the Yeywa Hydropower Reservoir as a case study. A detailed comparison has been made between the TVH rules, the $\mathrm{SOP}$ rule, the BSOP rule, the $\mathrm{SH}$ rule, the $\mathrm{DH}$ rule, the $\mathrm{OPH}$ rule, the TPH rule. The assessment of various reservoir operation performances for the applied rules was carried out. Based on the results, the TVH rules outperformed the other rules in terms of power generation for both summer and the entire study period. Moreover, the TVH rules were more sustainable than other rules, and the TVH-6 rule generated the highest electricity in 
both summer season and overall study period. Thus, it can be suggested that the TVH rules are promising for improving hydropower generation in the summer period.

Acknowledgements The authors would like to thank the EPGE, Myanmar, for providing the required data. Also, the authors would like to show their gratitude to anonymous reviewers for their valuable comments.

Author contribution Soe Thiha: Conceptualization, Methodology, Coding the model, Analysis, and Writing the original draft paper. Asaad.Y. Shamseldin and Bruce.W. Melville. Conceptualization, Supervision, Reviewing, and Editing the paper.

Funding Open Access funding enabled and organized by CAUL and its Member Institutions. The first author would like to thank to the New Zealand-ASEAN Scholarship program.

\section{Declarations}

\section{Competing Interest None.}

Open Access This article is licensed under a Creative Commons Attribution 4.0 International License, which permits use, sharing, adaptation, distribution and reproduction in any medium or format, as long as you give appropriate credit to the original author(s) and the source, provide a link to the Creative Commons licence, and indicate if changes were made. The images or other third party material in this article are included in the article's Creative Commons licence, unless indicated otherwise in a credit line to the material. If material is not included in the article's Creative Commons licence and your intended use is not permitted by statutory regulation or exceeds the permitted use, you will need to obtain permission directly from the copyright holder. To view a copy of this licence, visit http://creativecommons.org/licenses/by/4.0/.

\section{References}

AF-Colenco (2009) Yeywa Hydropower Project. Reservoir operation report, Report No.YHP-73-RSOP-APR $09,5-6$

Chong KL, Lai SH, Ahmed AN, Jaafar WZW, El-Shafie A (2021) Optimization of hydropower reservoir operation based on hedging policy using Jaya algorithm. Appl Soft Comput 106:107325

Deb K (2001) Multi-objective optimization using evolutionary algorithms. John Wiley \& Sons

Felfelani F, Movahed AJ, Zarghami M (2013) Simulating hedging rules for effective reservoir operation by using system dynamics: a case study of Dez Reservoir, Iran. Lake Reserv Manage 29(2):126-140

Hakimi D, Oyewola DO, Yahaya Y, Bolarin G (2016) Comparative analysis of genetic crossover operator in knapsack problem. J Appl Sci Environ Manag 20(3):593-596

Hashimoto T, Stedinger JR, Loucks DP (1982) Reliability, resiliency, and vulnerability criteria for water resource system performance evaluation. Water Resour Res 18(1):14-20

Jin Y, Lee S (2019) Comparative effectiveness of reservoir operation applying hedging rules based on available water and beginning storage to cope with droughts. Water Resour Manage 33(5):1897-1911

KOEI N (1999) Feasibility study on Yeywa Hydropower Project, Main Report, Volume 1, Tokyo, Japan

Loucks DP (1997) Quantifying trends in system sustainability. Hydrol Sci J 42(4):513-530

Lund JR (1996). Developing seasonal and long-term reservoir system operation plans using HEC-PRM., Hydrologic Engineering Center Davis, CA

MathWorks (2021) Global optimization toolbox: User's guide (2021). Retrieved 27 Jul 2021 from https://au. mathworks.com/help/pdf_doc/gads/index.html

McMahon TA, Adeloye AJ, Zhou SL (2006) Understanding performance measures of reservoirs. J Hydrol 324(1-4):359-382

Neelakantan T, Sasireka K (2013) Hydropower reservoir operation using standard operating and standard hedging policies. Int J Eng Techn 5(2):1191-1196

Sasireka K, Neelakantan TR (2016) Application of hedging rules in the operation of hydro-power reservoirs. Jordan J Civil Eng 10(3)

Shiau J (2009) Optimization of reservoir hedging rules using multiobjective genetic algorithm. J Water Resour Plan Manag 135(5):355-363 
Shih J, ReVelle C (1994) Water-supply operations during drought: Continuous hedging rule. J Water Resour Plan Manag 120(5):613-629

Srinivasan K, Philipose MC (1998) Effect of hedging on over-year reservoir performance. Water Resour Manage 12(2):95-120

Tayebiyan A, Ali TAM, Ghazali AH, Malek MA (2016) Optimization of exclusive release policies for hydropower reservoir operation by using genetic algorithm. Water Resour Manage 30(3):1203-1216

Tayebiyan A, Mohammad TA, Al-Ansari N, Malakootian M (2019) Comparison of optimal hedging policies for hydropower reservoir system operation. Water 11(1):121

Tu MY, Hsu NS, Tsai FTC, Yeh WWG (2008) Optimization of hedging rules for reservoir operations. J Water Resour Plan Manag 134(1):3-13

Publisher's Note Springer Nature remains neutral with regard to jurisdictional claims in published maps and institutional affiliations. 